\title{
Short-term glioblastoma cultures may contain normal "glia-like" cells
}

\author{
Sivakova $\mathrm{I}^{1}$, MacLeod $\mathrm{R}^{2}$, Mraz $\mathrm{P}^{1}$, Kubikova $\mathrm{E}^{1}$, Perzelova $\mathrm{A}^{1}$ \\ Department of Anatomy, Faculty of Medicine, Comenius University, Bratislava, Slovakia. \\ Anna.perzelova@fmed.uniba.sk
}

\section{ABSTRACT}

OBJECTIVES: Currently used glioblastoma cultures have many disadvantages and are being replaced by short-term cultures. However, these may include normal brain cells.

BACKGROUND: A comparative model of normal and glioma cultures is lacking. A significant contributory factor is because cultures from adult human brain contain small amounts of cells with glial phenotypes. The predominant population of flat or spindle shaped cells does not express glial markers and are often termed as "glia-like".

METHODS: Cryopreserved glioblastoma cultures from 28 bioptic samples were examined by immunofluorescence using antibodies to intermediate filaments (IF): glial fibrillary acidic protein (GFAP), cytokeratins (CK), nestin (Nes), vimentin (Vim) and neurofilaments (NF).

RESULTS: In short-term glioblastoma cultures GFAP-positive cells occured at higher percentages in 3/28 cultures and in lower percentages in further 5 cultures. Subpopulation of nestin positive cells were observed in all cultures and CK-positive cells were found in 25/28 cultures. All cells in all cultures were positively stained only for vimentin and negatively for NF. Cells grew slowly in 5 cultures which showed early proliferation arrest between passages 7 to 8 . A further 23 cultures showed growth arrest by passages 10 to 15 .

CONCLUSION: The presence of normal cells in short-term glioblastoma cultures may be caused by the infiltrative growth of these tumors. Our comparative analysis of morphological, growth and cytoskeletal properties revealed similarities between glioblastoma and normal brain cultures. In this study, the majority $(28 / 30)$ of short-term glioblastoma showed limited life spans, similar to normal cells lacking spontaneous immortalization. The use of short-term glioblastoma cultures has two main problematic areas: cultures may contain a major subpopulation of normal "glia-like" cells; or they may contain the inital phases of spontaneously immortalized glioblastoma cells bearing properties of permanent cell lines (Tab. 1, Fig. 2, Ref. 19). Text in PDF www.elis.sk.

KEY WORDS: glioblastoma, short-term cultures, human brain cultures, "glia-like" cells, intermediate filaments.

\section{Introduction}

Glioblastoma multiforme (GBM) is the most aggressive and intractable form of primary brain tumor, with remarkable interand intra-tumral heterogeneity. Progress in glioblastoma treatment requires improved understanding of intra-tumoral heterogeneity, in particular. GBM cell lines are often used in studies of glioma biology and to test potential therapeutic targets. However, the use of these cell models is problematic in several aspects: scientists of Uppsala University (whence the U-series of GBM cell lines originate) discovered that the DNA profile of one of the most

${ }^{1}$ Department of Anatomy, Faculty of Medicine, Comenius University, Bratislava, Slovakia, and ${ }^{2}$ Oldcroft House, Isle of Harris, HS3 3BP, United Kingdom

Address for correspondence: A. Perzelova, Department of Anatomy, Faculty of Medicine, Comenius University, Spitalska 24, SK-813 72 Bratislava, Slovakia.

Acknowledgement: Grant support: VEGA grant No. 1/3439/06 and ITMS: 26240120023, co-financed by the European Regional Development. profilic examples, U87MG, supplied by American Type Culture Collection (ATCC) was quite different from the original tumor. Hence, the validity of U87MG samples has been compromised due to misidentification. This bugbear of cell culture - cell line cross-contamination (CLCC) - is now known to be widespread and chronic (1). The recent publicity given to CLCC (2) together with the convenience of authentication by DNA profiling and availability of reference profile databanks should help mitigate this problem. Accordingly, the need for new GBM cell lines with well attested provenances and, ideally, reference tumor DNA/ RNA remains acute. Further problematic areas in studies using continuous glioblastoma cell lines are: cryptic contamination with mycoplasma with influence on cell growth (3); and, the validity of

Tab. 1. Indirect immunofluorescence staining for IF. The percentage of positive cells in normal brain (NB) and glioblastoma multiforme (GBM) cultures.

\begin{tabular}{lccccc}
\hline Cultures & GFAP & Nes & CK & Vim & NF \\
\hline NB & $0-0,1$ & $20-30$ & $0-70$ & 100 & 0 \\
GBM & $0-70$ & $30-40$ & $0-60$ & 100 & 0 \\
\hline
\end{tabular}



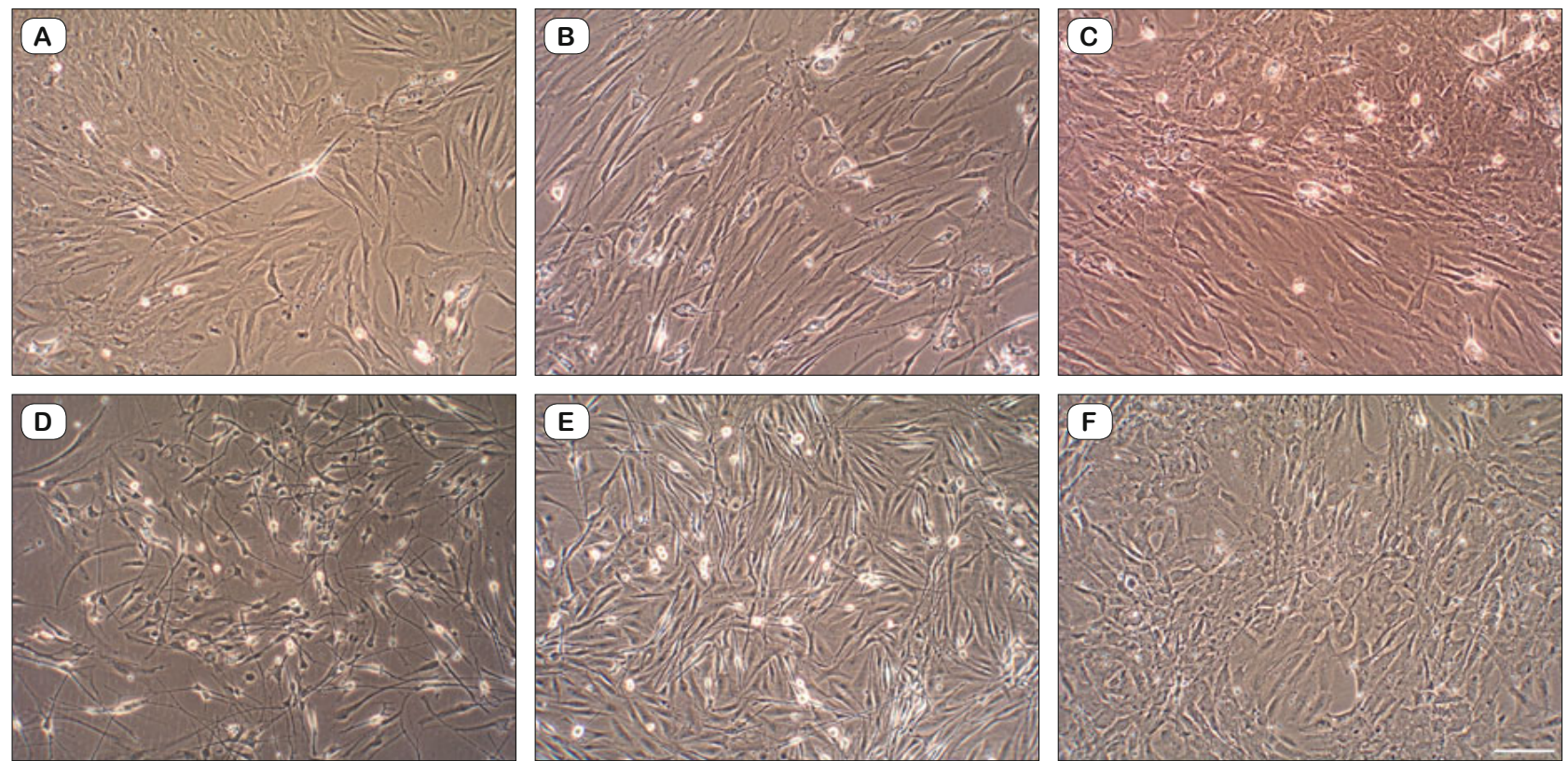

Fig. 1. Morphological features of living cells, phase-contrast microscopy. Normal adult human brain cultures (A-C): Astrocyte overlaying flat "glia-like" cells (A); ameboid microglia with grainy cytoplasm, and spindle shaped "glia-like" cells (B); confluent layer of "glia-like" cells (C). Glioblastoma short-term cultures (D-F): area of cells with astroglial mophology (D), spindle shaped (E) and flat cells (F). Scale bar $100 \mu \mathrm{m}$.
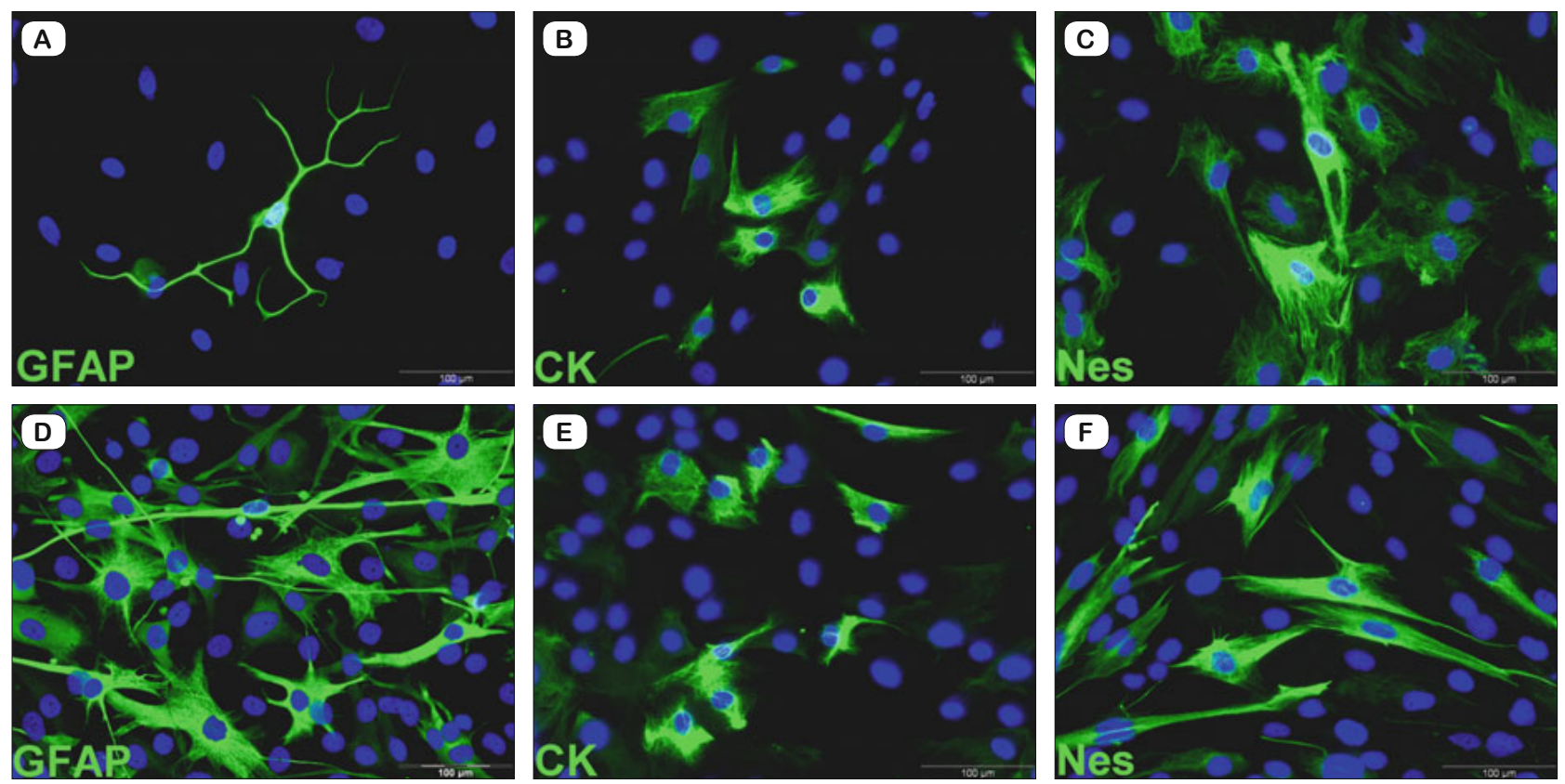

Fig. 2. Indirect immunofluorescence staining for IF. Normal human brain cultures (A-C): GFAP-positive astrocyte (A), CK-positive (B), and nestin-positive "glia-like" cells (C). Glioblastoma short-term cultures (D-F): GFAP-positive (D), CK-positive (E), and nestin-positive cells (F). Nuclei stained with Hoechst. Scale bars: $100 \mu \mathrm{m}$.

GBM cell lines to represent given molecular subtypes of primary human gliomas $(4,5)$. Several investigations have attempted to circumvent the above-mentioned problems by using short-term glioblastoma cultures.
Brain cell cultures derived from patients with non tumoral diagnoses have remain poorly defined. They are often termed as "glia-like" cells based on some morphological similarities to astrocytes. However, these cells do not express the critical marker 
GFAP $(6,7,8)$. In this study we compared the morphological, growth and cytoskeletal properties of glioblastoma and normal human brain short-term cultures.

\section{Materials and methods}

\section{Cell cultures}

Glioblastoma samples were kindly provided by the Department of Neurosurgery, Derer's Hospital, Bratislava. They were collected between 1993 to 2011. Experiments with human brain biopsies were performed according to Slovak laws 272/1994, $76 / 2004$ and approved by the Ethical Committee of UNB Bratislava. Bioptic samples were cut into small pieces and seeded in uncoated plastic dishes $\left(25 \mathrm{~cm}^{2}\right)$. Culture medium consisted of MEM with glutamine, nonessential amino acids and 10\% fetal calf serum (Sigma). Primary cultures and/or the cells in early passages were cryopreserved in liquid nitrogen. We recultured 30 cryopreserved glioblastoma cultures (from donor patients aged 39 to 74 years). From these cultures two permanent cell lines were established (170-MG-BA and 538-MG-BA). The remaining cultures showed limited life span. Cultures were passaged using $0.2 \%$ EDTA and $0.25 \%$ trypsin. Cells used for immunofluorescence staining were grown under the same conditions on uncoated glass coverslips.

\section{Immunofluorescence}

Indirect immunofluorescence using antibodies to IF was performed in all 28 cultures. Cells grown on coverslips were rinsed with PBS, fixed in methanol-acetone (1:1) solution for $15 \mathrm{~min}$ at $-15{ }^{\circ} \mathrm{C}$. We used the following antibodies: against GFAP, clone GF-01, 1:100 (Exbio, Prague), and polyclonal sera to GFAP, 1:100 (Dako); to vimentin clone V9, 1:100 (Sigma, Germany); to cytokeratins monoclonal anti-pan CK types: 1,4,5,6,8,10,13,18,19 (Sigma); to neurofilaments clone NF-01, 1:100 (Exbio); to nestin clone 25, 1:50 (BD Biosciences, USA) and polyclonal sera to nestin 1:100 (Millipore, USA). Secondary fluorescein-conjugated antibodies were purchased from Sigma and Sevapharma (Prague). Cells for indirect immunofluorescence were incubated $1 \mathrm{~h}$ with primary and $30 \mathrm{~min}$. with secondary antibodies. Nuclei were stained with Hoechst 33258 fluorochrome ( $5 \mu \mathrm{g} / \mathrm{ml}$ in PBS, Sigma) for $1 \mathrm{~min}$. To determine the percentage of immunoreactive cells, 30 fields were enumerated at 200x magnification, equally distributed over the coverslips fixed at different DIV and passage numbers. Fluorescence micoscopy was performed using an Olympus BX51 microscope (Olympus, Germany).

\section{Cell kinetics}

Proliferation rates were determined in three well proliferating cultures between passages 5 to 8 . Growth curves were constructed from counts of the harvested cells. For counting we used the cells from three dishes within DIV 1 to 5. Chamber cell counting was accomplished by enumerating 20 marked microscopic fields.

\section{Results}

Morphology of normal and glioblastoma tissue cultures

Cultured cells were assessed with inverse phase-contrast microscopy performed on living cells (Fig. 1A-F). Morphological features of primary normal adult human brain cultures are described in our previous study (8). Briefly, the cultures contained the following morphologically distinct cell types: astrocytes $(0-0.1$ $\%$ ), cells with long and thin processes (Fig. 1A); microglia/macrophages $(2-5 \%)$, ameboid cells with grainy or vacuolated cytoplasma Fig. 1B; and "glia-like" cells (95-98 \%), flat or spindle shaped cells (Fig. 1A-C). Glioblastoma cultures contained mainly flat and spindle shaped cells (Fig. 1E, F). Only several cultures in early passages contained areas of cells with astroglial morphology (Fig. 1D).

\section{Immunofluorescence staining}

All short-term gliobastoma cultures were examined for GFAP, vimentin (Vim), cytokeratins (CK), nestin (Nes) and neurofilaments (NF). The results of indirect immunofluorescence staining are summarized in Table 1 which, for comparative analysis, includes previously published immunostaining on normal adult human brain cultures $(8,9)$ (Fig. 2A-C). In glioblastoma cultures the GFAP-positive cells (50-70\%) occurred in 3/28 and at lower percentages $(5-10 \%)$ in further 5 cultures. Staining revealed the morphological variability of GFAP-positive cells (Fig. 2D). The number of GFAP-positive cells decreased subsequently, and completely disappeared in all cultures during passages 7 to 10 . CK were expressed in $25 / 28$ at $1-60 \%$ (Fig. 2E), while nestin was present in all cultures at 30-40\% (Fig. 2F).

\section{Cell growth}

Cells in short-term glioblastoma culture grew slowly in 5 cultures which showed early proliferation arrest between passages 7 to 8 . A further 23 cultures showed growth arrest by passages 10 to 15 . Population doubling times determined from growth curves in three well proliferating cultures between passage 5 to 8 and were approximately 30 to 36 hours. The cell growth was continuous without lag-phase which we described in glioblastoma cell lines (10).

\section{Discussion}

Recently we cultured 30 bioptic samples from GBM patients. From these samples we succeeded in establishing only two continuous cell lines, named as 170-MG-BA and 538-MG-BA (10). The remaining 28 cultures showed only limited life spans and ceased to grow between passage numbers 7 to 15 . In this study these cultures were analysed in comparison with our previous findings on normal human brain cultures $(8,11)$. Predominant cell populations in 25/28 non-immortalized glioblastoma cultures comprised mainly flat or spindle shaped cells and only the remaining three contained higher percentages of cells with thin and long processes typical of astroglial cells. Immunofluorescence staining with antibodies against IF showed distinct subpopulations of GFAP, nestin or cy- 
tokeratins positive cells. All cultured cells were positively stained only for vimentin and negatively for neurofilaments.

GFAP is considered to be the best marker for astroglial cells and astroglioma cultures, such as glioblastoma. However, most permanent human glioblastoma cell lines stain negatively for GFAP or lose GFAP expression after several passages $(10,12)$. Here, a high percentage of morphologically variable GFAP-positive cells were observed in $3 / 28$ cultures but only rarely in a further five cultures. However, GFAP-positive cells disappeared with increasing passage numbers in all cultures. CK are specific for normal and neoplastic epithelial cell differentiaton. But CK have also been reported in glioma tissue and cultures $(13,14,15)$. In this study CK-positive cells were present in 25/28 glioblastoma cultures at various percentages. Previously we described the unexpected presence of CK in 8/10 human brain cultures where 0.1 to $70 \%$ of "glia-like" cells positively stained with monoclonal anti-pan CK antibodies (9). Celullar dediferentiation is hallmark of cancer cells, however, CK expression in cultured normal brain cells is a sign of cellular dedifferentiaton which recapitulates the ectodermal origin of brain tissue. Nestin is currently considered as marker for neural stem cells (16). Here, nestin was found in all normal and glioblastoma cultures at approximately similar percentages.

The above-mentioned immunostaining, growth and morphological properties of glioblastoma cultures are comparable with the findings on normal adult human cultures prepared from brain tissue of patients with non-malignant diagnoses. Normal cultures contained only minor populations of morphologically distinct glial cell types ( 2 to $5 \%$ ) expressing specific markers accompanying a predominant population of GFAP-/vimentin+ "glia-like" cells (8). Similarly in normal "glia-like" and glioblastoma cultures the cells expressed nestin or cytokeratins at various percentages $(8,9)$. Differences were observed only in percentages of GFAP-positive cells. Normal adult human brain cultures always contained only small amounts of GFAP-positive cells which disappeared over several passages. GFAP-positive cells occurred at high percentages only in several glioblastoma cultures and as in normal cultures they disappeared by increased passage number.

Poor therapeutic outcomes in GBM demand new therapeutic approaches, more profound knowledge of glioma biology and optimalization of available cell models. Currently used glioma cell lines have critical disadvantages and are being replaced by short-term cultures defined as cultures surviving greater than three passages (17). Because of the high infiltrative potential of GBM, it is necessary to distinguish the normal from glioblastoma cells in a short-term cultures. Our results showed that mophological growth and IF immunostaining failed to demonstrate tumoral origin for short-term cultures.

A similar molecular profile has been described in short-term cultures and corresponding glioblastoma tissue (18). They examined four cultures with rapid and stable cell growth when cells attained at least ten passages. However, these cultures were selected from 36 short-term cultures. These findings correspond with our previous results demonstrating establishment of two permanent glioblastoma cell lines from 30 short-term cultures. Both cell lines originated during passage numbers 3 to 5 when there appeared areas of more rapidly proliferating cells which overgrew the remaining cells (10). We propose that in the afore- mentioned study (18) four short-term cultures were actually nascent continuous glioblastoma cell lines. As well as mutations of PTEN, TP53, EGFR, PIK3CA, PIK3R1, NF1, RB1, IDH1 and PDGFRA, Brennan et al. (19) reported a high incidence of alterations affecting the EGFR locus, of which the well known EGFRvIII subtype comprised 11 $\%$. In view of the limited availability of informative cytogenetic data, there is much scope for subjecting GBM cell lines to such molecular genetic analyses when attempting to characterize GBM cells at different stages of culture.

\section{References}

1. MacLeod RAF, Dirks WG, Matsuo Y, Kaufman M, Milch H, Drexler HG. Widespread intraspecies cross-contamination of human tumor cell lines arising at source. Int J Cancer 1999; 83 (4): 555-556.

2. Capes-Davis A, Theodosopoulos G, Atkin I, Drexler HG, Kohara A, MacLeod RA, Masters JR, Nakamura Y, Reid YA, Reddel RR, Freshney RI. Check your cultures! A list of cross-contaminated or misidentified cell lines. Int J Cancer 2010; 127 (1): 1-8. doi: 10.1002/ijc.25242.

3. Drexler HG, Uphoff CU. Mycoplasma contamination of cell culture: Incidence, sources, effects, detection, elimination, prevention. Cytotechnology 2002; 39 (2):75-90. doi: 10.1023/A:1022913015916.

4. Xie Y, Bergstrom T, Jiang Y, Johansson P, Marinescu VD, Lindberg N, Segerman A, Wicher G, Niklasson M, Baskaran S, Sreedharan S, Everlien I, Kastermar M, Hermasson A, Elfineh L, Libard S, Holland ECH, Hesselager G, Alafuzoff I, Westwrmark B, Nelander S, ForsbergNilsson K, Uhrbom L. The human glioblastoma cell culture resource: Validated cell models representing all molecular subtypes. EbioMedicine 2015; 2 (10): 1351-1363. doi: 10.1016/j.ebiom.2015.08.026.

5. Li A, Walling J, Kotliarov Y, Center A, Steed ME, Ahn SJ, Rosenblum M, Mikkelsen T, Zenklusen JC, Fine HA. Genomic changes and gene expression profiles reveal that establishes glioma cell lines are poorly representative of primary human gliomas. Mol Cancer Res 2008; 6 (1): 21-30. doi: 10.1158/1541-7786.

6. Ponten J, Westermark B. Properties of human malignant glioma cells in vitro. Med Biol 1978; 56 (4): 184-193.

7. Rutka JT, Kleppe-Hoiford H, Emma DA, Giblin JR, Dougherty DV, McCulloch JR, DeArmond SJ, Rosenblum ML. Characterization of normal human brain cultures. Lab Invest 1986; 55 (1): 71-85.

8. Perzelova A, Macikova I, Tardy M, Mraz P, Bizik I. Subpopulation of nestin positive glial precursor cells occur in primary adult human brain cultures. Biologia 2007; 62: 633-640.

9. Sivakova I, Perzelova A, Kubikova E, Mraz P. Unexpected presence of cytokeratins in human ,glia-like“ cells. Bratisl Med J 2013; 114 (5): 274-278. doi: 10.4149/BLL_2013_056.

10. MacLeod RAF, Schneider B, Sivakova I, Nagel S, Dirks WG, Mraz P, Kubikova E, Perzelova A. High level EGFR amplification in a newly established glioblastoma cell line: 170-MG-BA. Neoplasma 2019; 66 (1): 109-117. doi: 10.4149/neo_2018_180427N278.

11. Macikova I, Perzelova A, Mraz P, Steno J, Bizik I. Heterogeneity of keratin intermediate filaments expression in human glioma cell lines. Neoplasma 1999; 46: 390-393. 
12. Restrepo A, Smith CA, Agnihotri S, Shekarforousch M, Kongkham PN, Seol HJ, Northcott P, Rutka JT. Epigenetic regulation of glial fibrillary acidic protein by DNA methylation in human malignant gliomas. Neurooncol 2011; 13 (1): 42-50. doi: 10.1093/neuonc/noq145.

13. Mork SJ, Rubinstein LJ, Kepes JJ, Perentes E, Urhoff DF. Patterns of epithelial metaplasia in malignant gliomas. II. Squamous differentiation of epithelial-like formations in gliosarcomas and glioblastomas. J Neurophatol Exp Neurol 1988; 47 (2): 101-118.

14. Hirato J, Nakazato Y, Ogawa A. Expression of non-glial intermadiate filament proteins in gliomas. Clin Neuropathol 1994; 13 (1): 1-11.

15. Macikova I, Perzelova A, Mraz P, Steno J, Bizik I. Heterogeneity of keratin intermadate filaments expression in human glioma cell lines. Neoplasma 1999; 46 (6): 390-393.

16. Zhang M, Song T, Liang Y, Chen R, Wu L, Yang Z, Fang J. Nestin and CD133: valueble stem cell-specific markers for determining clinical outcome of glioma patients. J Exp Clin Cancer Res 2008; 27: 27-85. doi: 10.1186/1756-9966-27-85.

17. Farr-Jones MA, Parney IF, Petruk KC. Improved technique for establishing short term human brain tumor cultures. J Neurooncol 1999; 43 (1): $1-10$.
18. Cruvinel-Carloni A, Silva-Oliveira R, Torrieri R, Bidinotto LT, Berardinelli GN, Oliveira-Silva VA, Clara CA, deAlmeidaGC, Martinho O, Squire JA, Reis RM. Molecular characterization of short-term primary cultures and comparison with corresponding tumor tissue of Brazilian glioblastoma patient. Transl Cancer Res 2017; 6 (2): 332-345. doi: 10.21037/tcr.2017.03.32

19. Brennan CW, Verhaak RGW, McKenna A, Campos B, Noushmehr H, Salama SR, Zheng S, Chakravarty D, Sanborn JZ, Berman SH, Beroukhim R, Bernard B., Wu CHJ, Genovese G, Shmulevich I, Barnholtz-Sloan J, Zou L, Vegesna R, Shukla SA, Ciriello G, Yung WK, Zhang W, Sougnes C, Mikkelsen T, Aldape K, Bigner DD, Van Meir EG, Prados M, Sloan A, Black KL, Eschbacher J, Finocchiatro G, Friedman W, Andrews DW, Guha A, Iacocca M, O'Neill BP, Foltz G, Myers J, Weisenberger DJ, Penny R, Kucherlapati R, Perou CHM, Hayes DN, Gibbs R, Marra M, Mills GB, Lander E, Spellman P, Wilson R, Sander CH, Weinstein J, Meyerson M, Gabriel S, Laird PW, Haussler D, Getz G, Chin L. The somatic genomic landscape of glioblastoma. Cell 2013; 155 (2): 462-477. doi: 10.1016/j.cell.2013.09.034.

Received May 31, 2019. Accepted June 23, 2019. 